\title{
Abnormal Quantitative Sensory Testing is Associated With Persistent Pain One Year After TKA
}

\author{
Anthony Wright PhD, Penny Moss PhD, Karen Sloan MSc, Richard J. Beaver FRACS, \\ Jarle B. Pedersen MClinPhysio, Gerard Vehof MClinPhysio, Henrik Borge MClinPhysio, \\ Luca Maestroni MClinPhysio, Philip Cheong MManipTher
}

Received: 12 March 2014/ Accepted: 29 September 2014/Published online: 8 October 2014

(C) The Association of Bone and Joint Surgeons \& 2014

\begin{abstract}
Background Up to $15 \%$ of patients report at least moderate persistent pain after TKA. Such pain may be associated with the presence of widespread hyperalgesia and neuropathic-type pain.

Questions/purposes We asked if there was a difference among patients who report moderate to severe pain or no pain at least 12 months after TKA regarding (1) pressure pain threshold, (2) thermal (cold/heat) pain and detection thresholds, and (3) self-reported neuropathic pain.

Patients and Method Fifty-three volunteers were recruited from patients reporting no pain or moderate to severe pain, according to the Knee Society Score ${ }^{\odot}$. Differences between the moderate-to-severe and no-pain groups
\end{abstract}

Each author certifies that he or she has no commercial associations (eg, consultancies, stock ownership, equity interest, patent/licensing arrangements, etc) that might pose a conflict of interest in connection with the submitted article.

All ICMJE Conflict of Interest Forms for authors and Clinical

Orthopaedics and Related Research editors and board members are on file with the publication and can be viewed on request.

Each author certifies that his or her institution approved the human protocol for this investigation, that all investigations were conducted in conformity with ethical principles of research, and that informed consent for participation in the study was obtained.

The work was performed at the Joint Replacement Assessment Clinic, Shenton Park Campus, Royal Perth Hospital, Perth, Western Australia.

A. Wright, P. Moss ( (), J. B. Pedersen, G. Vehof, H. Borge,

L. Maestroni, P. Cheong

School of Physiotherapy and Exercise Science, Curtin

University, Kent Street, Bentley, Perth, WA 6102, Australia

e-mail: p.moss@exchange.curtin.edu.au; p.moss@curtin.edu.au

K. Sloan, R. J. Beaver

Joint Replacement Assessment Clinic, Royal Perth Hospital,

Perth, WA, Australia regarding pressure pain, heat and cold thresholds, and selfreported neuropathic-type pain were analyzed using independent t-tests.

Results Patients in the moderate-to-severe pain group exhibited reduced pressure pain threshold in the knee with the TKA $(p=0.025)$ and at the elbow $(p=0.002)$. This group also showed greater pain sensitivity to cold at the knee $(p=0.008)$ and elbow $(p=0.010)$, and increased heat pain sensitivity at the elbow $(\mathrm{p}=0.032)$. Cold and heat detection thresholds were impaired in this group at the elbow (cold, $\mathrm{p}=0.034$; heat, $\mathrm{p}=0.010$ ), although only heat detection was impaired at the knee $(\mathrm{p}=0.009)$. The moderate-to-severe pain group also reported more neuropathic-type pain $(\mathrm{p}=0.001)$.

Conclusion Persistent pain after TKA was associated with widespread pressure, cold hyperalgesia, and greater neuropathic-type pain.

Level of Evidence Level III, prognostic study.

\section{Introduction}

Although the majority of patients achieve substantial pain relief and improved function after TKA, a proportion continues to experience "life-disturbing" [29] persistent pain many years after surgery. The causes of this persistent pain are mostly unexplained.

Persistent postsurgical pain is defined by the International Association of the Study of Pain as pain after surgical intervention that lasts at least 2 months, with other causes of pain being excluded, particularly pain from a condition preceding the surgery [25]. Wylde et al. [43] reported that even after 3 to 4 years, $44 \%$ of patients were affected by some degree of persistent postsurgical pain, although much of the pain was mild, infrequent, and an 
improvement from preoperative pain. Liu et al. [23] found $20 \%$ of patients reported moderate to severe pain at rest and 33\% on activity after TKA, and Puolakka et al. [29] reported that $35.6 \%$ reported "daily life disturbing pain" 12 months after surgery. Of concern is the percentage of patients who report moderate to severe ongoing pain. Brander et al. [7] reported $13 \%$ of patients with "significant pain" 12 months after TKA and Wylde et al. [43] reported $15 \%$ of patients with "severe to extreme persistent pain" 3 to 4 years after surgery. Such persistent pain has been attributed to a wide range of intrinsic and extrinsic pre-, peri- or postoperative factors including preexisting depression or anxiety, genetic factors, surgical approach, prosthesis instability, or infection [19, 39].

However, it has been suggested that persistent severe pain may be indicative of a predominantly centrally driven pain process that may not be reversed with joint replacement [40, 41]. Hochman et al. [17] reported that some people with more severe knee osteoarthritis pain exhibit widespread hyperalgesia and report neuropathic-type pain. They reported that more than $19 \%$ of an unselected community-based sample of individuals with chronic osteoarthritis had features of neuropathic-type pain according to the PainDETECT questionnaire [11]. Other studies have found that neuropathic-type pain is closely associated with higher pain scores in individuals with knee osteoarthritis [27, 38]. Widespread mechanical hyperalgesia also has been shown to occur in patients with painful knee osteoarthritis, with a correlation between widespread mechanical hyperalgesia and self-reported pain $[2,14,16$, $26,36]$. Additionally, abnormalities in responses to heat or cold stimuli have been reported in individuals with knee osteoarthritis [20, 23]. It therefore appears that some patients with osteoarthritis may exhibit features associated with a neuropathic pain phenotype and it is possible that they may be predisposed to ongoing postoperative pain [40]. However, the degree to which this is so remains largely uncharacterized. An exploratory study by Wylde et al. [45] showed that preexisting pain sensitization may predict persistent pain after TKA. This supports an earlier finding of an association between preoperative elevated VAS pain response to an electrical stimulus and higher pain levels 18 months after TKA [24]. However, considerably more clarity is needed.

In this preliminary cross-sectional pilot study, we investigated if there was a difference between patients who continue to report moderate to severe pain or no pain according to the pain subscale of the Knee Society Score ${ }^{\odot}$ at least 12 months after TKA in (1) pressure pain threshold, (2) thermal (cold and heat) pain and detection thresholds, and (3) self-reported neuropathic pain.

\section{Patients and Methods}

Subjects

All subjects were recruited voluntarily from patients listed on the Joint Replacement Assessment Clinic registry at Royal Perth Hospital in Western Australia. Eligible patients had undergone TKA during the previous 12 to 36 months, had attended regular assessments at the Joint Replacement Assessment Clinic during the previous 6 months, and either had indicated no pain (none) or moderate to severe pain (moderate-occasional, moderatecontinuous, or severe) during the previous 4 weeks on the pain component of the Knee Society Score ${ }^{\odot}$. Subjects with mild pain according to the Knee Society Score ${ }^{\odot}$ were excluded from the study. Joint Replacement Assessment Clinic records include comprehensive medical data for all registry patients, therefore it was possible to exclude any potential participant with a history of stroke or hemophilia. Data regarding additional comorbidities such as chronic low back pain, fibromyalgia, diabetes, and depression were collected, but patients were not excluded for these comorbidities and all participants were advised to continue with their usual medications. Once a list of suitable patients was formulated, potential volunteers were provided with written information sheets and asked if they wished to participate in the study. Fifty percent of eligible patients with no pain and $30 \%$ with moderate to severe pain volunteered to participate. Ethical approval was granted by Royal Perth Hospital Human Research Ethics Committee and Curtin University Human Research Ethics Committee.

A total of 53 subjects were recruited for this pilot study, reflecting a sample of convenience. Basic demographic, comorbidities, quality of life, pain, and function data were collected on the day of testing (Table 1). Thirty-one subjects were recruited to the no-pain group comprising 13 males and 18 females, with a mean age of $70 \pm$ 7.25 years. Twenty-two subjects were recruited to the moderate-to-severe pain group comprising six males and 16 females, with a mean age of $70 \pm 7.07$ years.

The groups were compared regarding comorbidities, quality of life, pain, and functional limitations self-reported on the day of testing. The Self-administered Comorbidity Questionnaire was used to assess the presence (yes or no) of 12 general medical conditions (maximum 12) [32]. There was no difference between pain groups in the total number of comorbidities indicated $(\mathrm{p}=0.390)$ (Table 1$)$, nor was there any clear difference in the type of conditions reported by each group (Fig. 1). According to the European Quality of Life questionnaire (EQ-5D) [8], subjects with moderate to severe pain rated themselves as having a lower 
quality of life (Table $1 ; \mathrm{p}=0.018$ ). The EQ-5D consists of five questions related to mobility, self-care, pain, usual activities, and psychological status with three possible responses for each question to give a quality of life score (maximum 15). The EQ-5D also asks individuals to rate their overall state of health using a $100 \mathrm{~mm}$ VAS (maximum 100). Those in the moderate-to-severe pain group

Table 1. Demographic, questionnaire, and comorbidity data for test day 12 to 36 months after surgery

\begin{tabular}{llll}
\hline Data fields & $\begin{array}{l}\text { Moderate- } \\
\text { to-severe } \\
\text { pain group } \\
(\mathrm{n}=22)\end{array}$ & $\begin{array}{l}\text { No-pain } \\
\text { group } \\
(\mathrm{n}=31)\end{array}$ & t-test \\
& $6: 16$ & $13: 18$ & - \\
\hline Gender (M:F) & $69.8 \pm 7.1$ & $69.9 \pm 7.3$ & $\mathrm{p}=0.948$ \\
Age (years) & & & \\
Comorbidities & & & \\
$\quad$ Total reported (/12) & $2.77 \pm 1.82$ & $3.23 \pm 01.91$ & $\mathrm{p}=0.390$ \\
EQ-5D & & & \\
Quality of life (/15) & $2.27 \pm 0.32$ & $1.35 \pm 0.35$ & $\mathrm{p}=0.018^{*}$ \\
$\quad$ State of health (/100) & $73.77 \pm 3.48$ & $82.52 \pm 2.94$ & $\mathrm{p}=0.03^{*}$ \\
WOMAC & & & \\
Pain (/20) & $5.8 \pm 3.8$ & $2.1 \pm 2.2$ & $\mathrm{p}<0.0001^{*}$ \\
Stiffness (/8) & $2.7 \pm 1.9$ & $0.9 \pm 1.2$ & $($ all) \\
Function (/68) & $17.7 \pm 12.3$ & $6.1 \pm 6.6$ & \\
Total (/96) & $26.2 \pm 17.0$ & $9.2 \pm 8.8$ & \\
\hline
\end{tabular}

$\overline{\text { EQ-5D }=\text { European Quality of Life questionnaire score; }{ }^{1} \text { Self- }}$ reported Comorbidities questionnaire; ${ }^{2}$ score on test day; $* \mathrm{p}<0.05$. rated themselves as being in a less good state of health, compared with the no pain group (Table $1 ; \mathrm{p}=0.03$ ).

The WOMAC Osteoarthritis Knee Index was administered to compare each group's self-report of pain, stiffness, and functional limitation on the day of testing. The WOMAC is widely used and shows good internal validity and test-retest reliability [18]. The WOMAC index can be reported as a total score (maximum score 96) or as subscores for the subsections of pain (0-20), stiffness (0-8), or function (0-68). The moderate-to-severe pain group reported higher levels of pain and stiffness and reduced function (Table 1; $\mathrm{p}<0.001$ ). Preoperative WOMAC scores also were available from Joint Replacement Assessment Clinic records for 44 of the 53 subjects $(90 \%$ of the no pain group and $73 \%$ of the moderate-to-severe pain group). Independent t-tests showed that there were no differences between groups in WOMAC scores before surgery (Fig. 2). When percentage change in WOMAC from preoperative to test day score was evaluated, patients with no pain postoperatively showed an improvement across all subscores of $77.1 \%$ to $79.3 \%$ (Table 2), a result that compares favorably with pharmacologic studies, which report improvements in total WOMAC ranging from $36 \%$ to $45 \%[1,3,6,21]$. In contrast, the moderate-to-severe pain group showed improvement only across all subscores of $40.4 \%$ to $46.4 \%$, suggesting that this is a distinct group for whom removal of diseased tissue provides an incomplete solution.

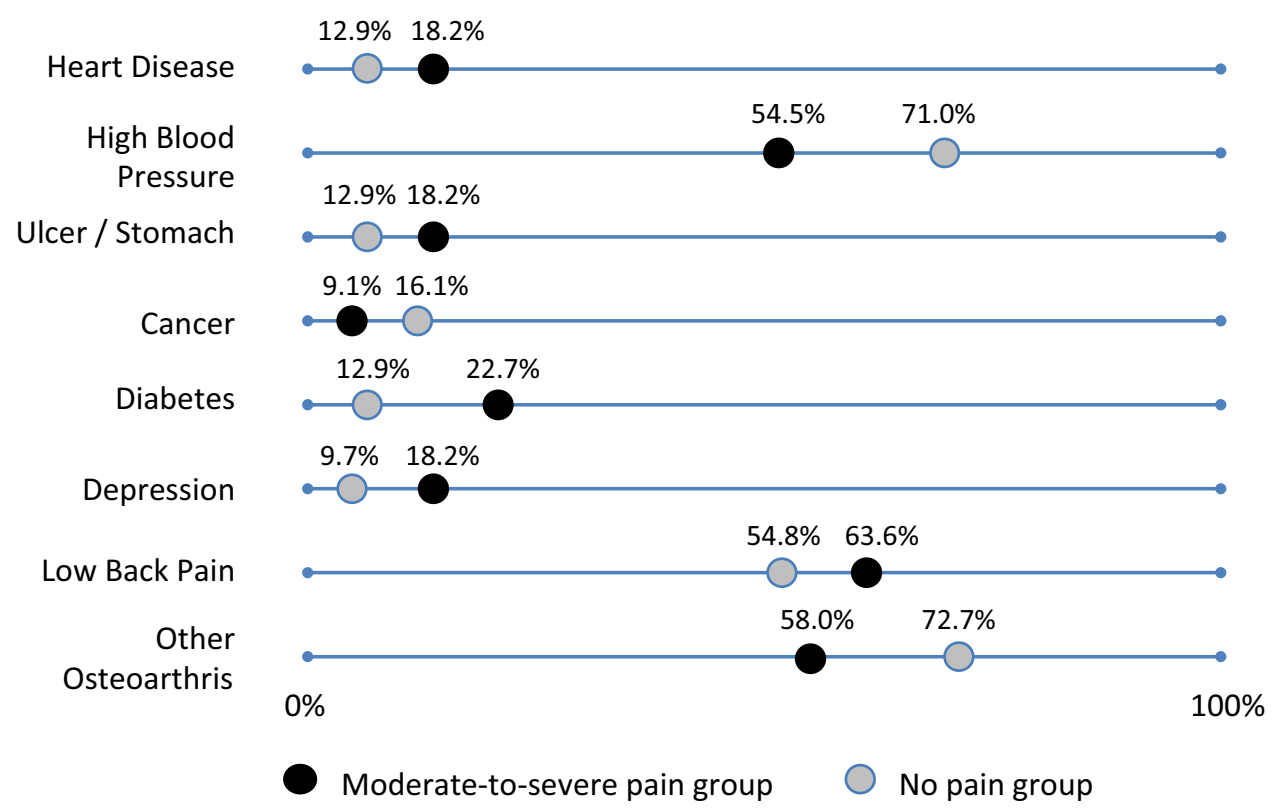

Fig. 1 Comorbid conditions, as reported by greater that $10 \%$ of subjects from the moderate-to-severe and no-pain groups, using the SelfAdministered Comorbidities Questionnaire, are shown. 


\section{Procedure}

A cross-sectional, observational design was used with all subjects attending one test session. Once informed consent was obtained, each subject completed five self-report questionnaires and then underwent the quantitative sensory tests, as described below. Additional preoperative WOMAC data were collected for each participant from the Joint Replacement Assessment Clinic documentation.

Testing was performed at one time for each patient, between 12 and 36 months after TKA as noted; no preoperative testing was performed in this cross-sectional pilot study.

\section{Physical Outcome Measures}

All quantitative sensory tests were performed at the medial joint line of the surgically treated knee and at a distant upper limb site over the extensor carpi radialis brevis muscle. The extensor carpi radialis brevis muscle has been used in previous quantitative sensory test studies [34, 35, 42, 43], and the site was located using the standardized method described by Riek et al. [31]. All quantitative

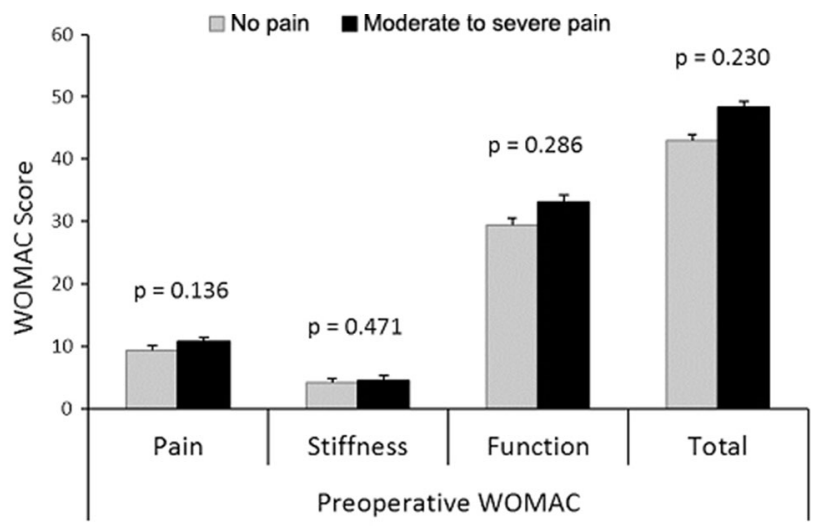

Fig. 2 Preoperative WOMAC scores for 44 of the participants in the moderate-to-severe pain $(\mathrm{n}=28)$ and no pain $(\mathrm{n}=16)$ groups are shown. sensory test measures were conducted with the subject lying in a relaxed position on a plinth. Pressure pain threshold testing was conducted with one practice trial on the tibialis anterior muscle followed by three measurements at the knee and three measures at the elbow (extensor carpi radialis brevis) site. Cold and heat detection and pain thresholds were collected as one practice followed by three trials at the elbow and the surgically treated knee. Site order was randomized between subjects for pressure pain threshold and thermal thresholds.

Pressure pain threshold was measured using a digital pressure algometer (Somedic, Sweden), a device that is recognized as a valid and reliable measure when used by a trained assessor [22, 28, 33]. Standard method and instructions were used [26]. The $1-\mathrm{cm}^{2}$ algometer probe was applied at a $90^{\circ}$ angle to the skin at a ramp of $40 \mathrm{kPa}$ / second. Subjects were asked to depress the handheld switch as soon as the sensation of pressure became painful. The mean of the three trials at each site was calculated for analysis.

Cold detection and cold pain thresholds were measured using a Peltier thermode (Medoc, Ramat Yishai, Israel). This thermode has been shown to be reliable and valid in quantitative sensory test studies [12,36, 42-45]. Standard method of limits and standardized instructions were used. The minimum temperature for the thermode was set at $0^{\circ} \mathrm{C}$. The $30-\times 30-\mathrm{mm}$ contact probe was attached to each test site with a reuseable self-adhering strap and subjects were given several minutes to adapt to the baseline temperature of $32^{\circ} \mathrm{C}$. When the device was activated, the thermode temperature decreased at a rate of $1^{\circ} \mathrm{C} /$ second. Cold detection threshold always was measured first to ensure intact sensory pathways. Subjects were instructed to depress the handheld switch as soon as they perceived any cooling change from baseline, thereby reversing the temperature back to baseline. For cold pain threshold, subjects were instructed to press the switch as soon as the cooling sensation changed to one of painful cold. For all thresholds, one practice trial was followed by three measurements, each separated by a randomly assigned pause between 3 and 6 seconds. The mean of the three trials was used for analysis.

Table 2. Percentage change from mean preoperative to mean postoperative WOMAC scores

\begin{tabular}{|c|c|c|c|c|c|c|}
\hline \multirow[t]{2}{*}{ WOMAC } & \multicolumn{3}{|c|}{ Moderate-to-severe pain group } & \multicolumn{3}{|l|}{ No pain group } \\
\hline & $\begin{array}{l}\text { Preoperative } \\
\text { Mean } \pm \text { SD }\end{array}$ & $\begin{array}{l}\text { Postoperative } \\
\text { Mean } \pm \text { SD }\end{array}$ & Change $(\%)$ & $\begin{array}{l}\text { Preoperative } \\
\text { Mean } \pm \text { SD }\end{array}$ & $\begin{array}{l}\text { Postoperative } \\
\text { Mean } \pm \text { SD }\end{array}$ & Change $(\%)$ \\
\hline Pain (20 points) & $10.8 \pm 3.0$ & $5.8 \pm 3.4$ & 46.3 & $9.3 \pm 3.0$ & $2.1 \pm 2.3$ & 77.2 \\
\hline Stiffness ( 8 points) & $4.5 \pm 1.6$ & $2.7 \pm 1.7$ & 40.4 & $4.1 \pm 1.7$ & $0.9 \pm 1.3$ & 77.1 \\
\hline Function (68 points) & $33.1 \pm 10.3$ & $17.7 \pm 10.4$ & 46.4 & $29.5 \pm 11.7$ & $6.1 \pm 6.2$ & 79.3 \\
\hline Total (96 points) & $48.3 \pm 11.6$ & $26.2 \pm 14.4$ & 45.8 & $42.9 \pm 15.2$ & $9.2 \pm 8.8$ & 78.6 \\
\hline
\end{tabular}


Heat detection and heat pain thresholds also were measured with the Medoc Peltier thermode using a similar method as for cold detection and pain thresholds (baseline $32^{\circ} \mathrm{C}, 1^{\circ} \mathrm{C} /$ second ascending ramp), with maximum temperature set at $50^{\circ} \mathrm{C}$. Heat detection threshold was tested before heat pain threshold, with heat detection threshold defined as the temperature $\left({ }^{\circ} \mathrm{C}\right)$ at which subjects first perceived an increase in warmth from baseline. Heat pain threshold was defined as the temperature $\left({ }^{\circ} \mathrm{C}\right)$ at which subjects perceived that the heating sensation had become painful. As soon as the subject pressed the switch to signal threshold, the temperature reversed to baseline. One practice was followed by three trials separated by variable pauses (3-6 seconds) [12]. The mean was calculated for analysis.

\section{Self-report Outcome Measures}

The PainDETECT neuropathic pain questionnaire [11] has been used to identify neuropathic pain components in a range of conditions. The questionnaire is a validated selfreport tool with a maximum total score of 35 . It has been shown to be a reliable screening tool with high sensitivity and specificity [11]. Participants completed a paper version of the questionnaire on the day of testing, before completion of the other evaluations.

\section{Statistical Analysis}

IBM SPSS ${ }^{\circledR}$ Statistics version 22 (Armonk, NY, USA) was used for the statistical analysis, with alpha set at $\mathrm{p}$ less than 0.05 . A priori calculations found that to detect a clinically relevant difference of $15 \%$ ( $\beta$ set at $0.80, \alpha<0.05$ ) between subjects in the control (no pain) and moderate-tosevere pain groups, a total sample of 56 was needed for pressure pain threshold and 50 for cold pain threshold. Given the considerably smaller standard deviations relative to means reported previously for heat pain threshold compared with pressure pain threshold or cold pain threshold [16, 36, 45], a total sample size of approximately 55 was considered more than adequate to power heat pain threshold analyses. With an actual total sample size of 53 for this study, post hoc actual differences between group means at the knee were $32.2 \%$ for $(\beta=0.84)$ and $71.0 \%$ for cold pain threshold $(\beta=0.86)$. For heat pain threshold however, post hoc power was more limited (knee $\beta=0.51$; elbow $\beta=0.68$ ).

Levenés test was used to confirm whether the data for each group showed equal variance. Degrees of freedom were corrected when equal variances were not assumed $(\mathrm{p}<0.05)$. Independent t-tests were used to analyze group differences in pressure pain threshold and WOMAC data. The remaining data were analyzed using Mann Whitney U-tests since the data were not normally distributed. Effect sizes were calculated using Cohen's d method [37].

\section{Results}

Pressure Pain Thresholds

Participants with moderate to severe pain showed heightened pressure pain sensitivity compared with those with no pain (Fig. 3). This was true at the knee that had the TKA ( $\mathrm{p}=0.025$; effect size, 0.61 ; moderate-to-severe pain group: mean, $282.64 \mathrm{kPa}$ [SD, 167.92]; no pain group: mean, $416.72 \mathrm{kPa}$ [SD, 254.83]) and at the distant elbow site ( $\mathrm{p}=0.002$; effect size, 0.91 ; moderate-to-severe pain group: mean $314.12 \mathrm{kPa}$ [SD, 139.63]; no pain group: mean, $454.06 \mathrm{kPa}$ [SD, 167.57]).

\section{Cold and Heat Thresholds}

The moderate-to-severe pain group showed elevated cold pain thresholds at the surgically treated knee and distant elbow sites, although group differences in heat pain and cold (Fig. 4) and heat detection thresholds (Fig. 5) were less clear. Mean cold pain threshold at the surgically treated knee was elevated for the moderate-to-severe pain group (mean, $9.23^{\circ} \pm 10.33^{\circ} \mathrm{C}$ ) compared with the no pain group (mean, $\left.2.68^{\circ} \pm 5.6^{\circ} \mathrm{C}\right)(\mathrm{p}=0.009$; effect size, $0.85)$. There were similar findings for cold pain threshold at the elbow (moderate-to-severe pain group: mean, $9.92^{\circ} \pm 10.07^{\circ} \mathrm{C}$; no pain group: mean, $2.86^{\circ} \pm 5.51^{\circ} \mathrm{C}$ [p $=0.010]$; effect size, 0.93). The moderate-to-severe pain group detected cold less quickly at the elbow ( $\mathrm{p}=0.034$; effect size, 0.63; moderate-to-severe pain group: mean, $25.79^{\circ} \pm 5.97^{\circ} \mathrm{C}$; no pain group, mean,

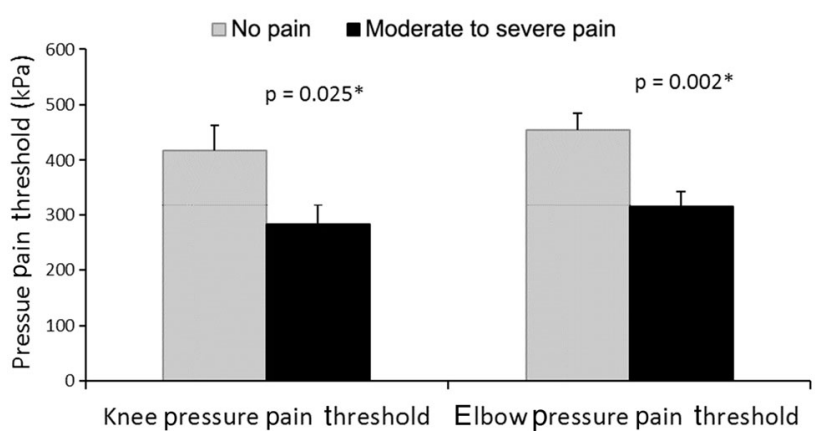

Fig. 3 Pressure pain threshold $(\mathrm{kPa})$ differences between the moderate-to-severe pain and no pain groups at the surgically treated knee and elbow are shown $(* \mathrm{p}<0.05)$. 
Fig. 4 Cold detection threshold $\left({ }^{\circ} \mathrm{C}\right)$ and cold pain threshold values $\left({ }^{\circ} \mathrm{C}\right)$ for the moderate-tosevere pain and no pain groups at the knee and elbow are shown $(* \mathrm{p}<0.05)$.

Fig. 5 Heat detection threshold $\left({ }^{\circ} \mathrm{C}\right)$ and heat pain threshold values $\left({ }^{\circ} \mathrm{C}\right)$ for the two pain groups at the knee and elbow are shown $(* p<0.05)$.
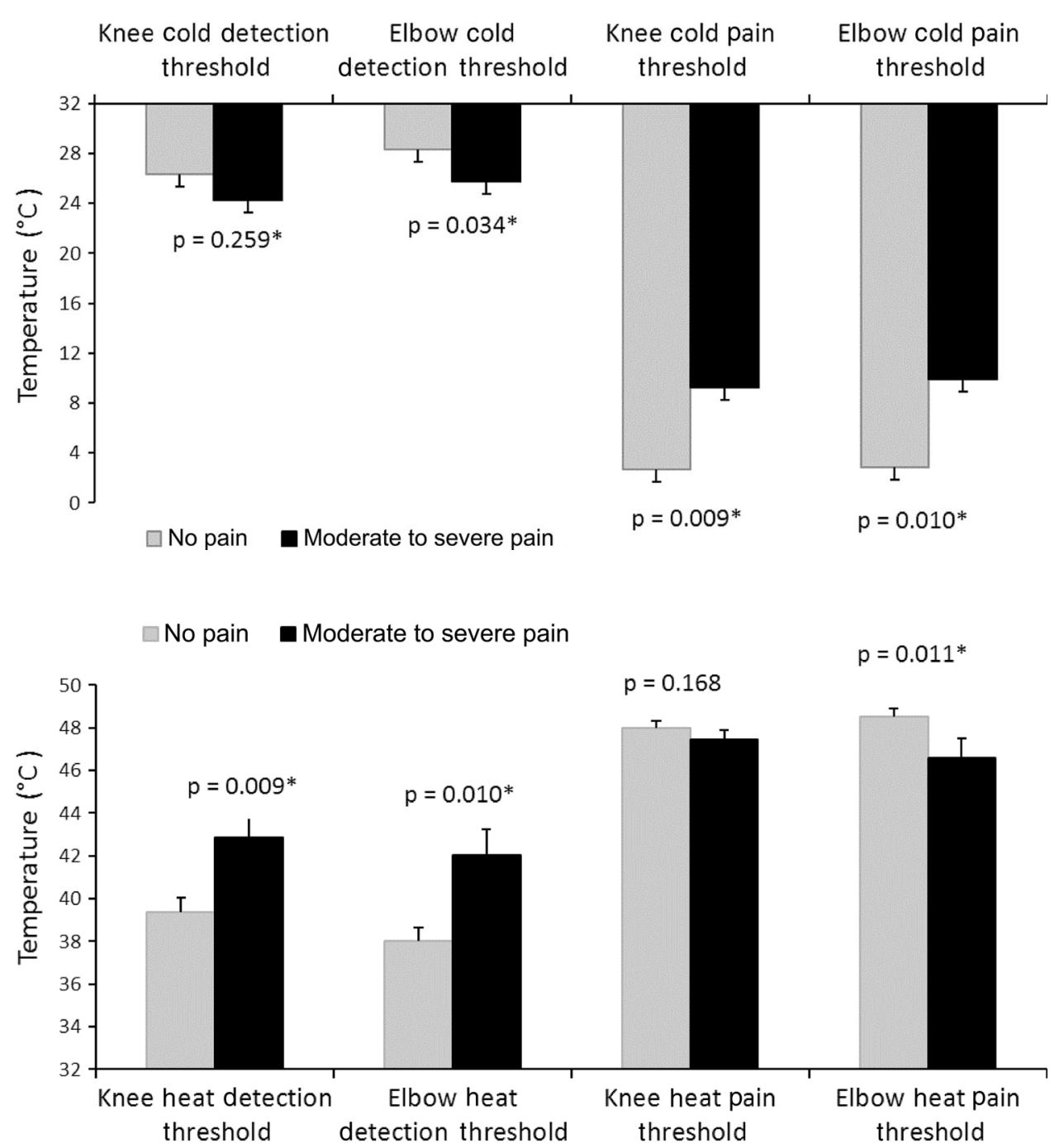

$\left.28.36^{\circ} \pm 2.12^{\circ} \mathrm{C}\right)$, but not at the knee $(\mathrm{p}=0.259$; moderate-to-severe pain group: mean, $24.23^{\circ} \pm 6.96^{\circ} \mathrm{C}$; no pain group: mean, $26.32^{\circ} \pm 3.89^{\circ} \mathrm{C}$ ). Heat pain threshold was lower (sensitized) for the moderate-tosevere pain group at the elbow (mean, $46.56^{\circ} \pm 4.0^{\circ} \mathrm{C}$ ) compared with the no pain group (mean, $48.54^{\circ} \pm 2.06^{\circ}$ C) $(\mathrm{p}=0.011$; effect size, 0.62). However there was no group difference in heat pain threshold at the surgically treated knee $(\mathrm{p}=0.168 ;$ moderate-to-severe pain group: mean, $47.48^{\circ} \pm 2.07^{\circ} \mathrm{C}$; no pain group: mean, $48.00^{\circ} \pm 1.97^{\circ} \mathrm{C}$ ). The moderate-to-severe pain group detected heat at a higher temperature than the no pain group at the knee $(\mathrm{p}=0.009$; effect size, 0.85 ; moderate-to-severe pain group: mean, $42.86^{\circ} \pm 4.61^{\circ} \mathrm{C}$; no pain group: mean, $39.36^{\circ} \pm 3.96^{\circ} \mathrm{C}$ ) and at the elbow ( $\mathrm{p}=0.010$; effect size, 0.91 ; moderate-to-severe pain group: mean, $42.05^{\circ} \pm 5.50^{\circ} \mathrm{C}$; no pain group: mean, $38.00^{\circ} \pm 3.70^{\circ} \mathrm{C}$ ).
Self-reported Neuropathic Pain

Individuals in the moderate-to-severe pain group reported higher levels of neuropathic-type pain as measured by PainDETECT (moderate-to-severe pain group: mean, $7.27 \pm 1.24 ;$ no pain group: mean, $3.03 \pm 0.65$; $\mathrm{p}=0.0010 ;$ effect size, 0.93).

\section{Discussion}

Persistent pain after a TKA may exist in $13 \%$ to $44 \%$ of patients $[4,7,29,41,45]$, and it has been suggested that this pain may be centrally driven [40]. Our cross-sectional study aimed to use pressure and thermal quantitative sensory tests and self-report questionnaires to determine if patients with moderate to severe pain 12 to 36 months after TKA exhibited signs of widespread hyperalgesia and neuropathic-type pain, 
compared with patients having no pain. We found that there was an association between postoperative self-report of moderate to severe pain and sensitized pressure and cold pain thresholds at the surgically treated knee and at the unaffected elbow. Heat detection threshold also was impaired in the moderate-to-severe pain group at both sites.

The limitations of this study must be acknowledged. Any cross-sectional study is limited by the inability to establish a temporal relationship between events and cannot determine causality or the direction of any associations. Consequently any findings need to be tested with a longitudinal study. We also experienced difficulties with recruitment, particularly of patients reporting moderate to severe pain, for whom attending a potentially uncomfortable test session may have been too daunting. Although the study was powered appropriately for pressure pain and cold pain threshold values at the knee, more equal group sizes would have been preferred. To optimize recruitment for a relatively short time, subjects were not asked to withdraw taking their usual pain medications before testing, a factor which might have influenced results. Although it might be hypothesized that analgesic washout would have increased the difference in pain sensitivity between patients with severe versus no pain, this hypothesis needs to be tested in a future study with total preassessment analgesic washout to clarify true extent of hyperalgesia and pain qualities. Although this study briefly compared comorbidities between pain groups, it was intended as a simple crosssectional pilot or feasibility study to look for difference trends in local and widespread quantitative sensory tests and self-reported neuropathic pain between patients reporting high or low levels of postoperative pain. A future, more comprehensive, study should take into consideration the large number of covariates that may influence the presence of persistent postoperative pain. These might include perioperative factors such as surgical approach and perioperative anesthesia $[9,19,39]$, psychological factors such depression or catastrophizing [10, 30, 39], and intrinsic factors such as gender, BMI, or high preoperative pain levels [31, 39].

We found that individuals who reported moderate to severe pain at least 12 months after TKA exhibited increased mechanosensitivity compared with individuals who reported no pain. This pressure hyperalgesia was increased at the surgically treated knee site and also at a distant, unaffected elbow site. Skou et al. [33] similarly found an association between pressure pain sensitivity at the lower leg and ongoing pain intensity in individuals who had undergone revision TKA. They also assessed additional measures of central sensitization and found that individuals with greater pressure sensitivity also exhibited less efficient conditioned pain modulation [33]. Our findings are further supported by the exploratory study by
Wylde et al. [45], which found a significant correlation between preoperative forearm pressure pain threshold and 1 -year WOMAC pain score in patients after TKA.

We also found an association between moderate to severe persistent postoperative pain and elevated cold pain thresholds at the knee and elbow and elevated heat pain thresholds at the elbow. To our knowledge no previous studies have evaluated cold pain thresholds in patients after TKA. However, some data exist to support an association between higher pain levels and the presence of cold hyperalgesia [13], however, more data regarding cold hyperalgesia is needed. Heat pain thresholds have been more widely investigated in osteoarthritis, although associations with persistent pain are equally unclear. We found that the moderate-to-severe pain group showed higher heat pain threshold at the elbow but not at the knee, although post hoc power was relatively low. Wylde et al. [44] assessed heat pain threshold at the knee and forearm but found no association with WOMAC pain score at 1 year. Rakel et al. [30], however, found that heat pain threshold at the affected knee was a significant predictor of postoperative movement pain.

Patients with persistent moderate to severe pain also exhibited impaired detection of cold and heat sensory changes. Reduced sensory acuity to heat sensation was found for the moderate-to-severe pain group at the knee and at the unaffected elbow site as was impaired cold detection at the elbow. Thermal sensory deficit may suggest damage to small diameter afferents or to central pain processing pathways [5]. Although some reduction in sensory acuity at the surgically treated knee might be expected, this was observed only for heat detection. Deficits in heat and cold detection at the elbow were not anticipated but provide an interesting avenue for future investigations.

The group differences in values for the PainDETECT neuropathic pain questionnaire suggest that the quality of pain experienced by subjects with persistent moderate to severe pain may differ. However, although these subjects reported higher levels of neuropathic-type pain symptoms, none scored positive for neuropathic pain (score $\geq 19$ ) and only four had scores in the 'unclear' classification (score 13-18). Patients with persistent moderate to severe pain in the current study therefore did not exhibit clear signs of the neuropathic-type pain. Comparable studies investigating presence of neuropathic-type pain after arthroplasty are limited. Haroutiunian et al. [15], in a systematic review, concluded that between $6 \%$ and $9 \%$ of patients report probable neuropathic pain after TKA or THA, supporting previous findings that $6 \%$ report positive signs on PainDETECT [44]. A recent study found that individuals with knee osteoarthritis with higher modified PainDETECT scores had increased odds of showing additional 
quantitative sensory test signs of central sensitization [16], however this has yet to be explored in patients with osteoarthritis after surgery.

Our cross-sectional study found that subjects with moderate to severe pain persisting up to 3 years after TKA exhibit widespread mechanical and cold and heat hyperalgesia. These subjects reported higher levels of neuropathic-type pain and only, on average, a 45\% improvement in WOMAC score. In contrast, patients without persistent pain do not exhibit such hyperalgesia or neuropathic-type pain and reported, on average, a $78 \%$ improvement in WOMAC score. These findings support the hypothesis that, even in the absence of peripheral nociceptive input from a degenerative joint, some patients continue to experience knee pain and associated dysfunction [40]. This preliminary study indicates that a larger and more comprehensive, preoperative to postoperative longitudinal study is warranted.

\section{References}

1. Altman RD, Zinsenheim JR, Temple AR, Schweinle JE. Threemonth efficacy and safety of acetaminophen extended-release for osteoarthritis pain of the hip or knee: a randomized, double-blind, placebo-controlled study. Osteoarthritis Cartilage. 2007;15:454461.

2. Arendt-Nielsen L, Nie H, Laursen MB, Laursen BS, Madeleine P, Simonsen $\mathrm{OH}$, Graven-Nielsen T. Sensitization in patients with painful knee osteoarthritis. Pain. 2010;149:573-581.

3. Babul N, Noveck R, Chipman H, Roth SH, Gana T, Albert K. Efficacy and safety of extended-release, once-daily tramadol in chronic pain: a randomized 12-week clinical trial in osteoarthritis of the knee. J Pain Symptom Manage. 2004;28:59-71.

4. Baker PN, van der Meulen JH, Lewsey J, Gregg PJ; National Joint Registry for England and Wales. The role of pain and function in determining patient satisfaction after total knee replacement: data from the National Joint Registry for England and Wales. J Bone Joint Surg Br. 2007;89:893-900.

5. Baron R, Binder A, Wasner G. Neuropathic pain: diagnosis, pathophysiological mechanisms, and treatment. Lancet Neurol. 2010;9:807-819.

6. Barthel HR, Haselwood D, Longley S 3rd, Gold MS, Altman RD. Randomized controlled trial of diclofenac sodium gel in knee osteoarthritis. Semin Arthritis Rheum. 2009;39:203-212.

7. Brander VA, Stulberg SD, Adams AD, Harden RN, Bruehl S, Stanos SP, Houle T. Predicting total knee replacement pain: a prospective, observational study. Clin Orthop Relat Res. 2003;416:27-36.

8. Busschbach JJ, McDonnell J, Essink-Bot ML, van Hout BA. Estimating parametric relationships between health description and health valuation with an application to the EuroQol EQ-5D. J Health Econ. 1999;18:551-571.

9. Chan, MT, Wan, AC, Gin T, Leslie K, Myles PS. Chronic postsurgical pain after nitrous oxide anesthesia. Pain. 2011;152:2514-2520.

10. Duivenvoorden T, Vissers MM, Verhaar JA, Busschbach JJ, Gosens T, Bloem RM, Bierma-Zeinstra SM, Reijman M. Anxiety and depressive symptoms before and after total hip and knee arthroplasty: a prospective multicentre study. Osteoarthritis Cartilage. 2013; 21:1834-1840.
11. Freynhagen R, Baron R, Gockel U., Tölle TR. painDETECT: a new screening questionnaire to identify neuropathic components in patients with back pain. Curr Med Res Opin. 2006;22:19111920.

12. Geber C, Klein T, Azad S, Birklein F, Gierthmühlen J, Huge V, Lauchart M, Nitzsche D, Stengel M, Valet M, Baron R, Maier C, Tölle T, Treede RD. Test-retest and interobserver reliability of quantitative sensory testing according to the protocol of the German Research Network on Neuropathic Pain (DFNS): a multi-centre study. Pain. 2011;152:548-556.

13. Goldsmith R, Wright C, Bell SF, Rushton A. Cold hyperalgesia as a prognostic factor in whiplash associated disorders: a systematic review. Man Ther. 2012;17:402-410.

14. Graven-Nielsen T, Wodehouse T, Langford RM, Arendt-Nielsen L, Kidd BL. Normalization of widespread hyperesthesia and facilitated spatial summation of deep-tissue pain in knee osteoarthritis patients after knee replacement. Arthritis Rheum. 2012;64:2907-2916.

15. Haroutiunian S, Nikolajsen L, Finnerup NB, Jensen TS. The neuropathic component in persistent postsurgical pain: a systematic literature review. Pain. 2013;154:95-102.

16. Hochman JR, Davis AM, Elkayam J, Gagliese L, Hawker GA. Neuropathic pain symptoms on the modified painDETECT correlate with signs of central sensitization in knee osteoarthritis. Osteoarthritis Cartilage. 2013; 21: 1236-1242.

17. Hochman JR, Gagliese L, Davis AM, Hawker GA. Neuropathic pain symptoms in a community knee OA cohort. Osteoarthritis Cartilage. 2011;19:647-654.

18. Jinks C, Jordan K, Croft P. Measuring the population impact of knee pain and disability with the Western Ontario and McMaster Universities Osteoathritis Index (WOMAC). Pain. 2002;100:5564.

19. Kehlet H, Jensen TS, Woolf CJ. Persistent postsurgical pain: risk factors and prevention. Lancet. 2006;367:1618-1625.

20. King CD, Sibille KT, Goodin BR, Cruz-Almeida Y, Glover TL, Bartley E, Riley JL, Herbert MS, Sotolongo A, Schmidt J, Fessler BJ, Redden DT, Staud R, Bradley LA, Fillingim RB. Experimental pain sensitivity differs as a function of clinical pain severity in symptomatic knee osteoarthritis. Osteoarthritis Cartilage. 2013;21: 1243-1252.

21. Kivitz A, Fairfax M, Sheldon EA, Xiang Q, Jones BA, Gammaitoni AR, Gould EM. Comparison of the effectiveness and tolerability of lidocaine patch $5 \%$ versus celecoxib for osteoarthritis-related knee pain: post hoc analysis of a 12 week, prospective, randomized, active-controlled, open-label, parallelgroup trial in adults. Clin Ther. 2008;30:2366-2377.

22. Lacourt TE, Houtveen JH, van Doornen LJ. Experimental pressure-pain assessments: test-retest reliability, convergence and dimensionality. Scand J Pain. 2012;3:31-37.

23. Liu SS, Buvanendran A, Rathmell JP, Sawhney M, Bae JJ, Moric M, Perros S, Pope AJ, Poultsides L, Della Valle CJ, Shin NS, McCartney CJ, Ma Y, Shah M, Wood MJ, Manion SC, Sculco TP. Predictors for moderate to severe acute postoperative pain after total hip and knee replacement. Int Orthop. 2012;36:22612267.

24. Lundblad H, Kreicbergs A, Jansson KA. Prediction of persistent pain after total knee replacement for osteoarthritis. J Bone Joint Surg Br. 2008; 90:166-171.

25. Macrae WA, Davies HTO. Chronic postsurgical pain. In: Crombie IK, Croft PR, Linton SJ, LeResche L, Von Korff M, eds. Epidemiology of Pain. Seattle, WA: IASP Press, International Association for the Study of Pain. 1999;125-142.

26. Moss P, Sluka K, Wright A. The initial effects of knee joint mobilization on osteoarthritic hyperalgesia. Man Ther. 2007;12:109-118. 
27. Ohtori S, Orita S, Yamashita M, Ishikawa T, Ito T, Shigemura T, Nishiyama H, Konno S, Ohta H, Takaso M, Inoue G, Eguchi Y, Ochiai N, Kishida S, Kuniyoshi K, Aoki Y, Arai G, Miyagi M, Kamoda H, Suzkuki M, Nakamura J, Furuya T, Kubota G, Sakuma Y, Oikawa Y, Suzuki M, Sasho T, Nakagawa K, Toyone T, Takahashi K. Existence of a neuropathic pain component in patients with osteoarthritis of the knee. Yonsei Med J. 2012;53: 801-805.

28. Persson AL, Brogårdh C, Sjölund BH. Tender or not tender: testretest repeatability of pressure pain thresholds in the trapezius and deltoid muscles of healthy women. J Rehabil Med. 2004;36:17-27.

29. Puolakka PA, Rorarius MG, Roviola M, Puolakka TJ, Nordhausen K, Lindgren L. Persistent pain following knee arthroplasty. Eur J Anaesthesiol. 2010;27:455-460.

30. Rakel BA, Blodgett NP, Bridget Zimmerman M, Logsden-Sackett N, Clark C, Noiseux N, Callaghan J, Herr K, Geasland K, Yang X, Sluka, KA. Predictors of postoperative movement and resting pain following total knee replacement. Pain. 2012;153:2192-2203.

31. Riek S, Carson RG, Wright A. A new technique for the selective recording of extensor carpi radialis longus and brevis EMG. J Electromyogr Kinesiol. 2000;10:249-253.

32. Sangha O, Stucki G, Liang MH, Fossel AH, Katz JN. The SelfAdministered Comorbidity Questionnaire: a new method to assess comorbidity for clinical and health services research. Arthritis Rheum. 2003;49:156-163.

33. Skou ST, Graven-Nielsen T, Lengsoe L, Simonsen O, Laursen MB, Arendt-Nielsen L. Relating clinical measures of pain with experimentally assessed pain mechanisms in patients with knee osteoarthritis. Scand J Pain. 2013;4:111-117.

34. Slater H, Arendt- Nielsen L, Wright A, Graven-Nielsen T. Experimental deep tissue pain in wrist extensors: a model of lateral epicondylalgia. Eur J Pain. 2003;7:277-288.

35. Slater H, Arendt-Nielsen L, Wright A, Graven-Nielsen T. Sensory and motor effects of experimental muscle pain in patients with lateral epicondylalgia and controls with delayed onset muscle soreness. Pain. 2005;114:118-130.

36. Suokas AK, Walsh DA, McWilliams DF, Condon L, Moreton B, Wylde V, Arendt-Nielsen L, Zhang W. Quantitative sensory testing in painful osteoarthritis: a systematic review and metaanalysis. Osteoarthritis Cartilage. 2012;20:1075-1085.

37. Thalheimer W, Cook S. How to calculate effect sizes from published research articles: a simplified methodology. 2002. Available at: http://work-learning.com/effect_sizes.htm. Accessed August 24, 2014.

38. Valdes AM, Suokas AK, Doherty SA, Jenkins W, Doherty M. History of knee surgery is associated with higher prevalence of neuropathic pain-like symptoms in patients with severe osteoarthritis of the knee. Semin Arthritis Rheum. 2014; 43:588-592.

39. Vilardo L, Shah M. Chronic pain after hip and knee replacement. Tech Reg Anesth Pain Manag. 2011;15:110-115.

40. Woolf CJ. Central sensitization: implications for the diagnosis and treatment of pain. Pain. 2011;152(suppl):S2-S15.

41. Wylde V, Dieppe P, Hewlett S, Learmonth ID. Total knee replacement: is it really an effective procedure for all? Knee. 2007; 14:417-423.

42. Wylde V, Hewlett S, Learmonth ID, Dieppe P. Persistent pain after joint replacement: prevalence, sensory qualities, and postoperative determinants. Pain. 2011;152:566-572.

43. Wylde V, Palmer S, Learmonth ID, Dieppe P. Test-retest reliability of Quantitative Sensory Testing in knee osteoarthritis and healthy participants. Osteoarthritis Cartilage. 2011;19:655658.

44. Wylde V, Palmer S, Learmonth ID, Dieppe P. Somatosensory abnormalities in knee OA. Rheumatology (Oxford). 2012;51:535543.

45. Wylde V, Palmer S, Learmonth ID, Dieppe P. The association between pre-operative pain sensitisation and chronic pain after knee replacement: an exploratory study. Osteoarthritis Cartilage. 2013;21: 1253-1256. 